\title{
Case Report \\ Two Patients with Extremely Elevated Tumor Markers: Where Is the Malignancy?
}

\author{
Patrick P. J. van der Veek, ${ }^{1}$ Wouter H. de Vos tot Nederveen Cappel, ${ }^{2}$ \\ Alexandra M. J. Langers, ${ }^{3}$ and Bart van Hoek ${ }^{3}$ \\ ${ }^{1}$ Departments of Internal Medicine, Gastroenterology, and Hepatology, Medisch Centrum Haaglanden, P.O. Box 432, \\ 2501 CK The Hague, The Netherlands \\ ${ }^{2}$ Department of Gastroenterology and Hepatology, Isala Clinics, P.O. Box 10500, 8000 GM Zwolle, The Netherlands \\ ${ }^{3}$ Department of Gastroenterology and Hepatology, Leiden University Medical Center, 2300 RC Leiden, The Netherlands \\ Correspondence should be addressed to Patrick P. J. van der Veek, p.vanderveek@mchaaglanden.nl
}

Received 3 March 2011; Accepted 26 April 2011

Academic Editor: Stuart Sherman

Copyright ( 2011 Patrick P. J. van der Veek et al. This is an open access article distributed under the Creative Commons Attribution License, which permits unrestricted use, distribution, and reproduction in any medium, provided the original work is properly cited.

\begin{abstract}
Serum tumor markers are useful to evaluate a cancer's response to treatment, for early detection of cancer relapse, and, in some cases, to diagnose malignancy. In this paper, we present two patients with significantly elevated serum tumor markers without evidence of malignant disease. An 18-year-old patient suffering from autoimmune hepatitis had markedly increased alphafetoprotein (aFP) levels $(2,002 \mu \mathrm{g} / \mathrm{L}$; normal $<10 \mathrm{ug} / \mathrm{L})$. Extensive imaging showed no signs of hepatocellular carcinoma or other cancer, and treatment with Prednisone led to rapid normalization of both liver enzymes and aFP. The second patient, a 60-year-old female with painless jaundice due to biliary stone disease, had very high serum levels of CA19-9 $(18,000 \mathrm{kU} / \mathrm{L}$, normal $<27 \mathrm{kU} / \mathrm{L})$. Liver biochemistry and serum CA19-9 concentration decreased to almost normal values (45 kU/L) after biliary stenting. These cases demonstrate that serum tumor markers can be elevated in benign disease and are therefore not appropriate to diagnose cancer.
\end{abstract}

\section{Introduction}

Serum tumor markers are useful to evaluate a cancer's response to treatment, for early detection of cancer relapse, and, in some cases, to diagnose malignancy. Here, we present two patients with significantly increased serum tumor markers without evidence of malignant disease.

\section{Case A}

An 18-year-old male patient was admitted for progressive jaundice, which had started after an episode of binge drinking during a holiday in Italy 5 months before presentation. Jaundice had been intermittently present since but had worsened during the last few weeks. He suffered from unusual fatigue and nonspecific upper abdominal pain that was not related to meal ingestion. Urine and stools were normal. On admission, he had stopped drinking alcohol for several months and denied any drug abuse. Physical examination showed a mild jaundice but was otherwise unremarkable. Laboratory tests revealed a mild macrocytic anemia (hemoglobin $7.3 \mathrm{mmol} / \mathrm{L}$ (normal (N) $8.5-11.0 \mathrm{mmol} / \mathrm{L}), \quad \mathrm{MCV} 101 \mathrm{fl}(\mathrm{N} 80-100 \mathrm{fl})$, and marked elevation of liver biochemistry (total bilirubin $100 \mu \mathrm{mol} / \mathrm{L} \quad(\mathrm{N} \quad 0-17 \mu \mathrm{mol} / \mathrm{L})$, conjugated bilirubin $64 \mu \mathrm{mol} / \mathrm{L}$ ( $\mathrm{N} 0-5 \mu \mathrm{mol} / \mathrm{L}$ ), alkaline phosphatase (ALP) $155 \mathrm{U} / \mathrm{L}$ (N 40-120 U/L), gamma-GT (gGT) 254 U/L (N 5-55 U/L), aspartate aminotransferase (AST) 1,025 U/L (N 5-35 U/L), alanine aminotransferase (ALT) 656 U/l (N 5$45 \mathrm{U} / \mathrm{L})$ ). Antibodies against smooth muscle (ASMA) and nuclei (ANA) were positive, and gamma globulin level was elevated (IgG, 25.1 g/L; N 7.0-16.0 g/L)), suggesting autoimmune hepatitis. Anti-DNA was negative. Remarkably, alphafetoprotein (aFP) concentration, which was routinely measured in the standard workup for patients with liver enzyme abnormalities, was also significantly increased to $2,002 \mu \mathrm{g} / \mathrm{L}$ 
(upper limit of normal (ULN) $10 \mu \mathrm{g} / \mathrm{L}$ ). Test results for hepatitis A, B, and C, Epstein-Barr virus, Cytomegalovirus, and antimitochondrial antibodies were all negative. No evidence was found for Wilson's disease, hemochromatosis; alfa-1-antitrypsine genotype was partly deficient (PI-MS) but quantitative analysis was normal. Urinalysis was also completely normal. Abdominal ultrasound showed normal liver parenchyma without focal liver lesions and no signs of portal hypertension. Because of the extraordinary aFP increase, an additional abdominal CT scan was performed to exclude hepatocellular carcinoma (HCC), seminoma, and nonseminomatous germ cell tumor, all of which could not be demonstrated. Liver biopsy showed a periportal and lobular inflammatory infiltrate, piecemeal necrosis, abundance of plasma cells, and extensive collapse of liver parenchyma confirming the diagnosis of autoimmune hepatitis. Immediately after biopsy, Prednisone $40 \mathrm{mg}$ once daily was started, which led to rapid improvement and, eventually, normalization of liver biochemistry. Interestingly, aFP levels also decreased rapidly at the same rate as ALT (Figure 1). Prednisone was slowly tapered with synchronous introduction of Azathioprine. At present, complete remission is maintained with Prednisone 2,5 mg and Azathioprine $150 \mathrm{mg}$ once daily.

\section{Case B}

A 60-year-old female patient was admitted to a regional hospital for painless jaundice, pruritus, and weight loss after a period of epigastric pain. Physical examination showed no abnormalities other than jaundice. Liver biochemistry was consistent with obstructive jaundice (total bilirubin $62 \mu \mathrm{mol} / \mathrm{L}$, conjugated bilirubin $41 \mu \mathrm{mol} / \mathrm{L}$, ALP $549 \mathrm{U} / \mathrm{L}, \mathrm{gGT} 950 \mathrm{U} / \mathrm{L}, \mathrm{AST} 74 \mathrm{U} / \mathrm{L}$, ALT $332 \mathrm{U} / \mathrm{L}$ ) but also showed extreme elevation of Cancer Antigen (CA) 19-9 $(18,000 \mathrm{kU} / \mathrm{L}, \mathrm{ULN} 27 \mathrm{kU} / \mathrm{L})$. Abdominal ultrasound showed multiple stones in the gallbladder and a $13 \mathrm{~mm}$ stone in the distal cystic duct; there were no signs of cholecystitis. Both the common hepatic duct and intrahepatic ducts were dilated. During admission, liver enzymes improved spontaneously and the patient was discharged, awaiting cholecystectomy. However, she was readmitted with a relapse of painless jaundice before surgery had been performed. Abdominal CT scan now showed a dilated CBD and intrahepatic ducts, but no signs of malignancy. MRCP revealed a $13 \mathrm{~mm}$ distal CBD stone. The patient was transferred to our hospital when she developed cholangitis. At ERCP, stone removal from the CBD was impossible due to the size of the gallstone, and a biliary endoprosthesis was placed. Serum CA19-9 concentration decreased to almost normal values $(45 \mathrm{kU} / \mathrm{L})$ after biliary stenting. One month later she was readmitted for relapse of cholangitis after endoprothesis luxation. Again, CA19-9 was $>10,000 \mathrm{kU} / \mathrm{L}$ and returned to almost normal $(45 \mathrm{kU} / \mathrm{L})$ after stent placement. A second attempt for endoscopic crushing and stone extraction was not successful, and she eventually underwent cholecystectomy with choledochotomy and stone removal. No signs of malignancy were detected during surgery. The histopathology of the removed gallbladder showed

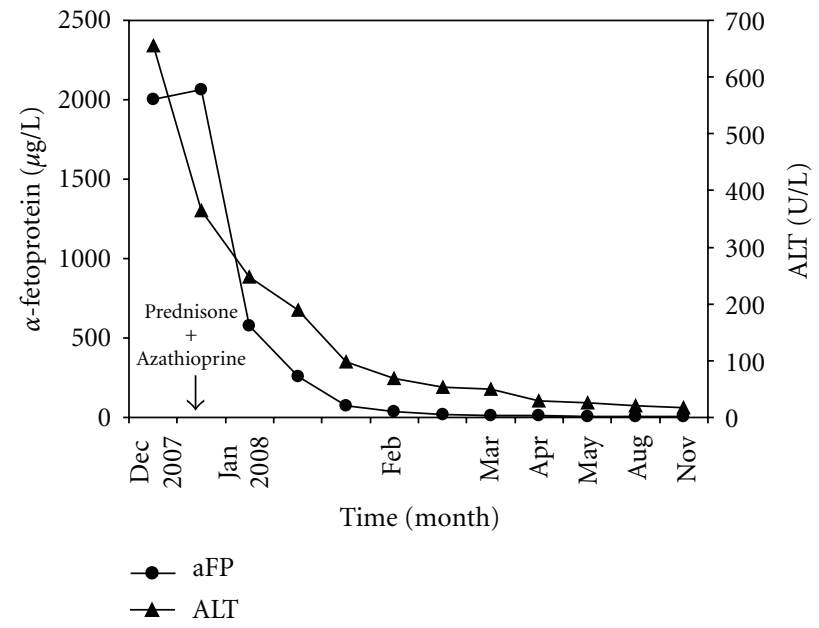

FIGURE 1: Serum alpha-fetoprotein (aFP) and alanine aminotransferase (ALT) concentrations in an 18-year-old male patient with autoimmune hepatitis. Both markers normalized in several months after treatment with Prednisone and Azathioprine was started.

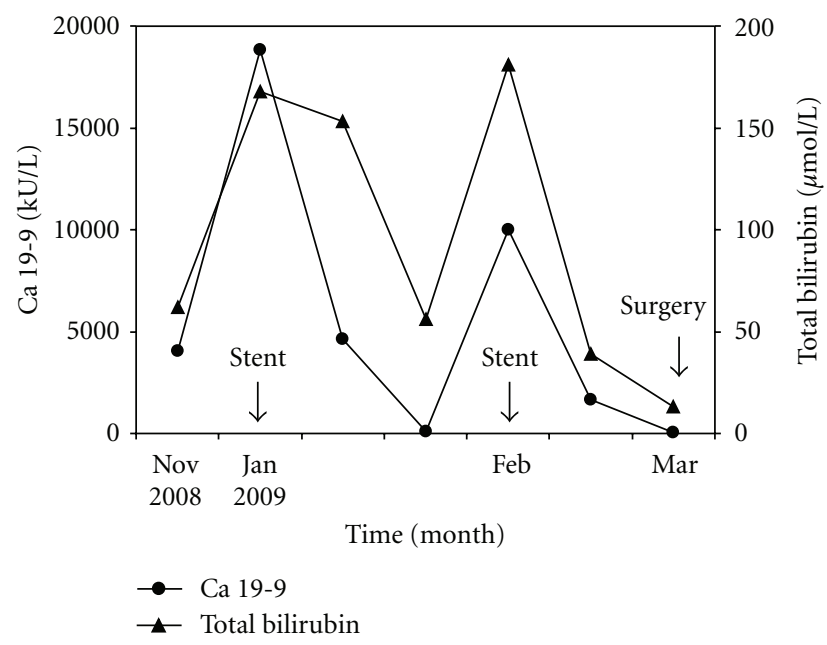

Figure 2: Serum Cancer Antigen 19-9 (CA 19-9) and total bilirubin concentrations in a 60-year-old female patient with obstructive jaundice due to a large biliary stone. Both markers rapidly decreased after endoscopic placement of a biliary endosprothesis. Surgery was performed in March 2009.

cholecystolithiasis and signs of chronic inflammation. Serum levels of bilirubine, and CA19-9 are shown in Figure 2.

\section{Discussion}

Alpha-fetoprotein is a 68-kilodalton polypeptide that is produced in the fetal liver and yolk sac. Serum levels of aFP are undetectable in healthy individuals but can be increased in a number of conditions, including hepatocellular carcinoma (HCC), seminoma and nonseminomatous germ cell tumors, and gastric, biliary, and pancreatic cancers. Levels of aFP can also be slightly elevated (up to $500 \mu \mathrm{g} / \mathrm{L}$ ) in pregnancy, reflecting fetal production, or sometimes higher 
in several obstetric complications. Increased levels can also be present in chronic viral hepatitis. For instance, up to $17 \%$ of patients with chronic hepatitis $\mathrm{C}$ infection and advanced fibrosis or cirrhosis without evidence for HCC have modest elevation of serum aFP concentrations, which improve upon treatment with pegylated interferon alpha$2 \mathrm{a}$ and ribavirin [1]. In general, serum concentrations $>400 \mu \mathrm{g} / \mathrm{L}$ in high-risk patients (cirrhosis, chronic hepatitis B infection) in the presence of a focal lesion of more than $2 \mathrm{~cm}$ with arterial hypervascularization on one imaging modality are considered diagnostic for HCC [2]. Lower levels in patients with HCC are common, and normal serum aFP concentrations can be found in a significant number of patients with HCC [3]. False positive results may occur in alcohol and drug abuse and other states of chronic liver damage, but values are usually $<100 \mu \mathrm{g} / \mathrm{L}$.

Development of HCC in preexisting autoimmune hepatitis can cause serum aFP elevation as was reported previously [4-7]. Cirrhosis was present in almost all of these patients [4-6] or not reported [7]. In our case, however, liver biopsy did not demonstrate fibrosis or cirrhosis, and abdominal ultrasound and CT scan showed no underlying malignancy as an explanation for the rise in aFP. Non-malignant serum aFP elevation may result from altered hepatocyte-hepatocyte interaction and loss of normal architectural arrangement, such as seen in fibrosis and cirrhosis [8] or, as in our case, widespread liver tissue collapse. In contrast, experiments in regenerating mouse liver tissue after CCI4 poisoning demonstrated that aFP-producing cells were normally differentiated hepatocytes without any structural signs of damage [9]. Thus, liver tissue regeneration during hepatic inflammation may be an alternative explanation for the rise in serum aFP in our patient with autoimmune hepatitis.

To our knowledge, this paper is the first to describe a patient with autoimmune hepatitis and this extreme elevation of serum aFP up to levels suggestive of HCC $(>400 \mu \mathrm{g} / \mathrm{L})$ in whom no malignancy was found. Both liver biochemistry and aFP normalized following treatment with high-dose glucocorticoids. A recent report described a 59-year-old patient with a synchronous diagnosis of systemic lupus erythematosus (SLE) and autoimmune hepatitis in whom aFP levels were modestly elevated $(320 \mu \mathrm{g} / \mathrm{L})$ [10]. In this patient, levels of aFP returned to normal within weeks after treatment with Prednisone $30 \mathrm{mg} /$ day and Azathioprine $100 \mathrm{mg} /$ day was started. Our patient had no signs of other underlying autoimmune diseases.

CA19-9, a tumor-associated antigen, is recognized by the monoclonal antibody 116NS-19-9. The antigenic determinant on CA19-9 that is recognized by $116 \mathrm{NS}-19-9$ is a sialylated lacto- $\mathrm{N}$-fucopentaose II, the so-called sialyl Lewis antigen. CA19-9 is used as a tumor marker of cancers in the gastrointestinal tract, such as pancreatic and biliary tract cancers, and colon, esophageal, and hepatic carcinomas. CA19-9 levels may also be elevated in several benign conditions in individuals with the Lewis antigen positive phenotype. These include inflammation or proliferation of noncancerous tissue, probably due to hypersecretion by normal epithelial cells (i.e., pancreatitis, pancreatic cysts, cholangitis, bronchiectasis, and pulmonary fibrosis) and obstruction of CA19-9 discharge pathways. The correlation between serum CA19-9 levels and serum cholestasis parameters (ALP, bilirubin) is well established, and CA199 elevation in biliary obstruction is probably caused by leakage of biliary mucins into the serum (i.e., pancreatic or biliary duct stenosis due to gallstones). Malfunction in organs that metabolize CA19-9 (chronic hepatitis, chronic glomerulonephritis) may also lead to elevated serum levels of CA19-9 [11]. Generally, levels greater than 1,000 kU/L are rare in benign conditions, although one study found CA199 levels of $>1,000 \mathrm{U} / \mathrm{ml}$ to be present in $4.7 \%$ of patients with cholangitis or cholestasis secondary to benign disease [11-13].

On initial presentation, our patient probably had obstructive jaundice due to Mirizzi's syndrome. CA19-9 was routinely measured in the workup for painless jaundice and was extremely elevated to a maximum of $18,000 \mathrm{kU} / \mathrm{L}$. Only one previous case report demonstrated highly increased levels of CA19-9 in a patient with Mirizzi's syndrome [14]. The clear correlation between serum concentrations of CA19-9, ALP and bilirubin, with normalization after biliary stent placement in the absence of tumor on CT-scan and ERCP, strongly suggests that the elevation of CA19-9 was due to cholestasis and not caused by malignant disease.

In conclusion, these two cases not only demonstrate that tumor markers can be elevated in benign disease but also emphasize that elevated serum tumor markers alone are not suitable for establishing a diagnosis of malignancy.

\section{Abbreviations}

$\begin{array}{ll}\text { aFP: } & \text { Alpha-fetoprotein } \\ \text { ALT: } & \text { Alanine aminotransferase } \\ \text { ALP: } & \text { Alkaline phosphatase } \\ \text { AST: } & \text { Aspartate aminotransferase } \\ \text { CA 19-9: } & \text { Cancer Antigen 19-9 } \\ \text { CBD: } & \text { Common bile duct } \\ \text { HCC: } & \text { Hepatocellular carcinoma } \\ \text { N: } & \text { Normal values } \\ \text { ULN: } & \text { Upper limit of normal. }\end{array}$

\section{Conflict of Interset}

No conflict of interests exists for any of the authors.

\section{References}

[1] A. M. Di Bisceglie, R. K. Sterling, R. T. Chung et al., "Serum alpha-fetoprotein levels in patients with advanced hepatitis $\mathrm{C}$ : results from the HALT-C trial," Journal of Hepatology, vol. 43, no. 3, pp. 434-441, 2005.

[2] J. Bruix, M. Sherman, J. M. Llovet et al., "Clinical management of hepatocellular carcinoma: conclusions of the Barcelona2000 EASL conference: European Association for the Study of the Liver," Journal of Hepatology, vol. 35, no. 3, pp. 421-430, 2001.

[3] D. S. Chen, J. L. Sung, J. C. Sheu et al., "Serum alphafetoprotein in the early stage of human hepatocellular carcinoma," Gastroenterology, vol. 86, no. 6, pp. 1404-1409, 1984. 
[4] K. Yamazaki, T. Kamiyama, S. Shiba et al., "An aged male patient with autoimmune hepatitis complicated by hepatocellular carcinoma," Internal Medicine, vol. 38, no. 5, pp. 422425, 1999.

[5] Y. Motoo, T. Wakatsuki, N. Tanaka et al., "Resected case of hepatocellular carcinoma associated with lupoid hepatitis," Journal of Gastroenterology and Hepatology, vol. 4, no. 3, pp. 295-298, 1989.

[6] A. W. Jakobovits, P. R. Gibson, and F. J. Dudley, "Primary liver cell carcinoma complicating autoimmune chronic active hepatitis," Digestive Diseases and Sciences, vol. 26, no. 8, pp. 694-699, 1981.

[7] J. Meza-Junco, A. J. Montaño-Loza, B. Martínez-Benitez, and E. Kimura-Hayama, "Hepatocellular carcinoma in patients with autoimmune liver diseases: two case reports and literature review," Annals of Hepatology, vol. 6, no. 2, pp. 122-126, 2007.

[8] N. S. Goldstein, D. E. Blue, R Hankin et al., "Serum alpha-fetoprotein levels in patients with chronic hepatitis $\mathrm{C}$ : relationships with serum alanine aminotransferase values, histologic activity index, and hepatocyte MIB-1 scores," American Journal of Clinical Pathology, vol. 111, no. 6, pp. 811-816, 1999.

[9] N. V. Engelhardt, V. N. Baranov, M. N. Lazareva, and A. I. Goussev, "Ultrastructural localisation of alpha-fetoprotin (AFP) in regenerating mouse liver poisoned with CCL4. 1: reexpression of AFP in differentiated hepatocytes," Histochemistry, vol. 80, no. 4, pp. 401-407, 1984.

[10] F. C. Liu, D. M. Chang, J. H. Lai et al., "Autoimmune hepatitis with raised alpha-fetoprotein level as the presenting symptoms of systemic lupus erythematosus: a case report," Rheumatology International, vol. 27, no. 5, pp. 489-491, 2007.

[11] S. Ito and F. Gejyo, "Elevation of serum CA19-9 levels in benign diseases," Internal Medicine, vol. 38, no. 11, pp. 840$841,1999$.

[12] D. V. Mann, R. Edwards, S. Ho, W. Y. Lau, and G. Glazer, "Elevated tumour marker CA19-9: clinical interpretation and influence of obstructive jaundice," European Journal of Surgical Oncology, vol. 26, no. 5, pp. 474-479, 2000.

[13] H. J. Kim, M. H. Kim, S. J. Myung et al., "A new strategy for the application of CA19-9 in the differentiation of pancreaticobiliary cancer: analysis using a receiver operating characteristic curve," American Journal of Gastroenterology, vol. 94, no. 7, pp. 1941-1946, 1999.

[14] A. Principe, M. Del Gaudio, G. L. Grazi, U. Paolucci, and A. Cavallari, "Mirizzi syndrome with cholecysto-choledocal fistula with a high CA19-9 level mimicking biliary malignancies: a case report," Hepato-Gastroenterology, vol. 50, no. 53, pp. 1259-1262, 2003. 


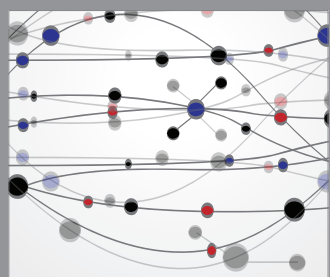

The Scientific World Journal
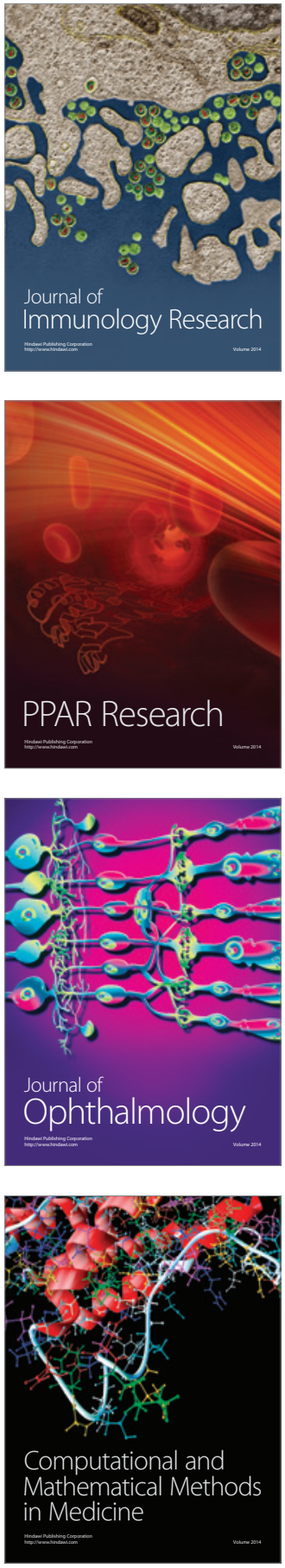

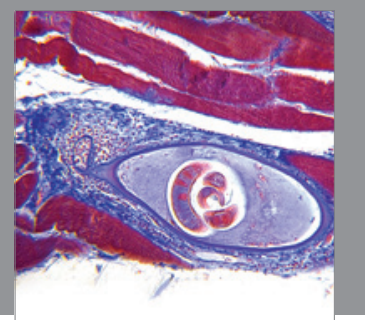

Gastroenterology

Research and Practice
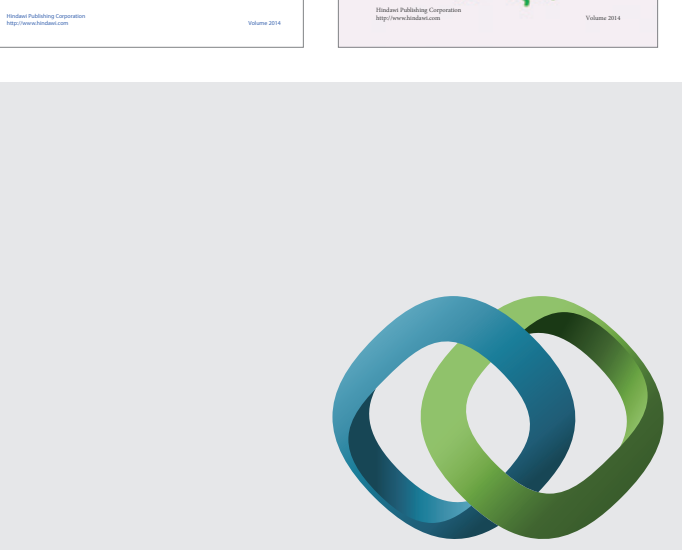

\section{Hindawi}

Submit your manuscripts at

http://www.hindawi.com
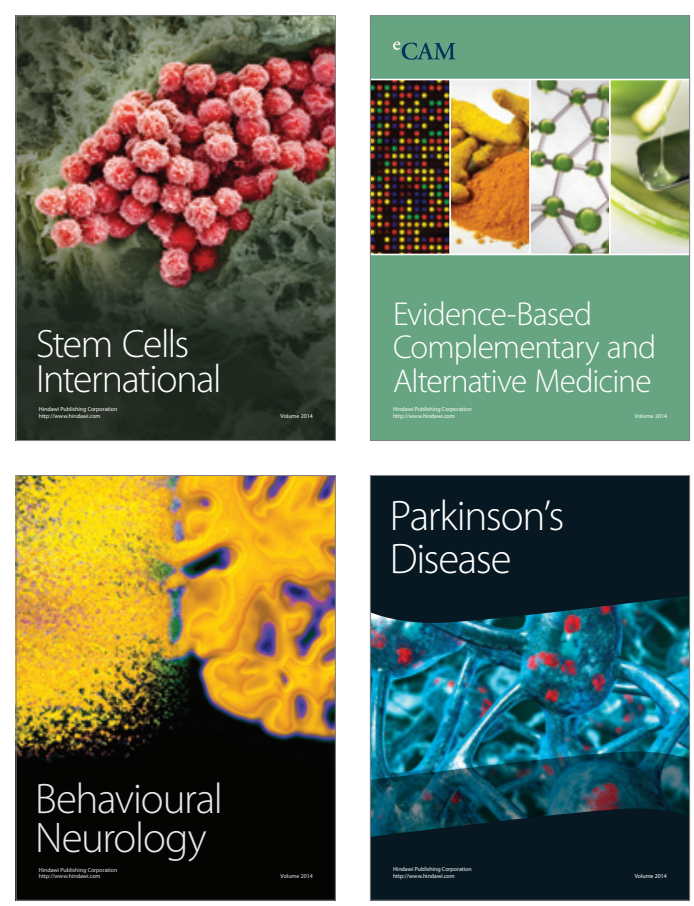

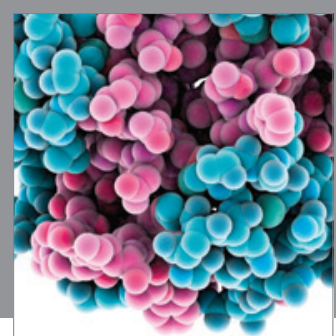

Journal of
Diabetes Research

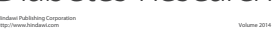

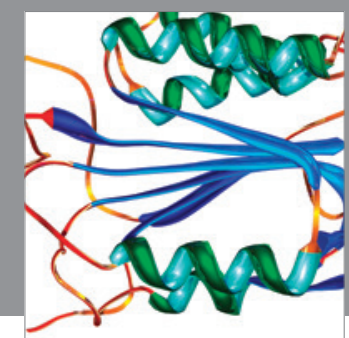

Disease Markers
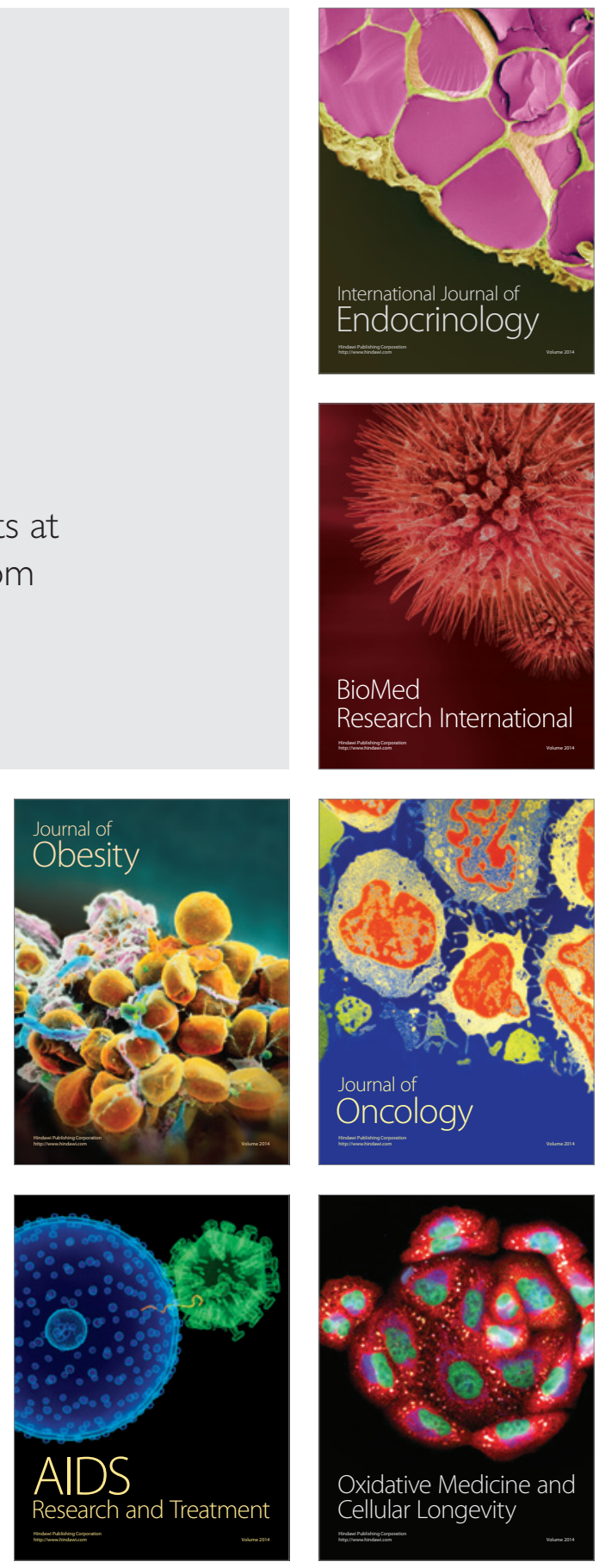